\title{
Evaluation of Antidiarrhoeal Potentioal of Azadirachta Indica Stem Bark Extact in Rats
}

\author{
Mr. Ankit Dhama ${ }^{1}$, Dr. Shamim Ahmad, Mr. Praveen Kumar, Dr. Ashish K. Paharia \\ 09997747518 \\ JSRHKJSRHK@Gmail.Com \\ Translam Institute of Pharmaceutical Education and Research, Meerut \\ Dr. APJ Abdul Kalam Technical University, Lucknow (India) \\ DOI: 10.29322/IJSRP.10.03.2020.p9913 \\ http://dx.doi.org/10.29322/IJSRP.10.03.2020.p9913
}

\begin{abstract}
The present study was undertaken to evaluate the antidiarrhoeal potential of Azadirachta indica stem bark extract against the several experimental models of diarrhoea in rats. I've studies the effect of aqueous extract of the stem bark of the Azadirachta indica in the castor oil induced diarrhoea model Weight and the amount of intestinal content induced by castor oil was studied entropolating method. Gastrointestinal infection rate was expressed as percentage of longest distance obtained by charcoal divided by total length of the small intestine. The three method was use for detect the antidiarrhoeal activity that was castor oil induced diarrhoea, gastrointestinal motility and $\mathrm{PGE}_{2}$ induced enteropooling. The aqueous extract shows significant activity against the castor oil induced diarrhoea. A significant reduction was also found gastrointestinal motility in small intestine transit test and a significant inhibition was found in $\mathrm{PGE}_{2}$ enteropooling. Results obtained in study quantify the antidiarrhoeal effect of aqueous extract of Azadirachta indica stem bark and its use by traditional practitioner's treatment of diarrhea.
\end{abstract}

\section{KEYWORDS}

Azadirachta indica, Antidiarrhoeal potential, Stem bark aqueous extract, Castor oil, Loperamide drug.

\section{INTRODUCTION}

Diarrhoea is the disorder of digestive system which is characterised by defecation, frequent, high of fluid fecal matter that is watery stools. The primary cause is greater intestinal motility with less time for absorption and the delivery of a large volume of fluid to the large intestine overloading its capacity to absorb salts and water. It may be caused from any intestinal infections, any allergy, also improper dieting, any toxicological agents etc. ${ }^{1}$

Diarrhoea occurs from the imbalance between of the absorption and secretary mechanisms in the intestinal tract resulting in an excessive lose of the fluid in the faeces. The inhibition of diarrhoea experimentally depends on potential antidiarrhoeal agent pharmacologically. Some antidiarrhoeal agents act by reduction of gastrointestinal motility and also secretion. ${ }^{2}$

Acute diarrhoeal is most frequent in adults, it's create most frequent health problem of travellers and dehydration and electrolyte disturbance is common in all causes of acute diarrhoea. Antidiarrhoeals not be used in children's because they do not reduce the electrolyte and fluid loss and also cause adverse effects. When diarrhoea are persisting for longer then one month is known as chronic diarrhoea. In this type of diarrhoea mild malabsorption syndrome and tropical enteropathy are causes. Its appears in most healthy indigenous populations of tropical countries. Chronic diarrhoea causes non infection including gluten sensitivity and inherited metabolic disorders like inflammatory bowel diseases in the majority. ${ }^{3}$

The Ayurvedic pharmacopoeia mentioned more than 1200 species of plants in which the antidiarrhoeal activity found. Acharya Charka has mentioned a group of plants of antidiarrhoeal activity named as Purish Samgarahania Mahakasashaya.

The castor oil induced diarrhoea model used in this study is logical because the autacoids and prostaglandins cause the diarrhoea in human beings, so this model appears the similarity with the diarrhoea in human beings. ${ }^{4}$

The aqueous extracts of Azadirachta indica stem bark showed the significant inhibitory effect against the castor oil and show the significant reduction effect in gastrointestinal motility during the charcoal meal test and also show significant inhibits $\mathrm{PGE}_{2}$ induced enteropooling. The results of present study of aqueous extracts of Azadirachta indica stem bark showed the inhibitory activity of diarrhoea. 


\section{MATERIALS AND METHODS}

Plant Material: The stem bark of Azadirachta indica was collected from Village Pabla, Distt Baghpat, Uttar Pradesh (India). The crude stem bark sample of Azadirachta indica was Authenticated by Dr. Sunita Garg, Chief Scientist, Raw Material and Herbarium And Museum, Delhi (RHMD), Council of Scientific and Industrial Research - National Institute of Science Communication and information Resources (CSIR - NISCAIR), Satsang Vihar Marg, New Delhi, with the Ref. No. NISCAIR/RHMD/Consult/2018/3139-88 Dt. 18/01/2018.

\section{Chemicals reagents and drugs used}

Atropine sulphate and Loperamide, castor oil, normal saline $(\mathrm{NaCl} 0.9 \% \mathrm{w} / \mathrm{v})$ and charcoal, aqueous gum acacia, PGE2, $\mathrm{NaOH}$, Distilled Water etc.

\section{Animals}

Wistar rats of either sex weight of $200 \mathrm{~g}-250 \mathrm{~g}$ was selected. The rats were fasted for overnight before every experiment. The experimental protocols were approved by the International Animal Ethical committee with the reference no. of protocol IAEC/PH-17/TIPER/101 Dt. 25-08-2017. These animals were housed in polypropylene boxes under standard conditions of light cycle $(12 \mathrm{~h}$ light , $12 \mathrm{~h}$ dark $)$ and temperature $\left(20^{\circ} \mathrm{C} \pm 2^{\circ} \mathrm{C}\right)$, for least 7 days before the experiments. Animals were acclimatized for laboratory conditions before experiment testing's.

\section{Experimental procedures for antidiarrhoeal activity \\ Acute oral toxicity study}

According to the Environmental Protection Agency (EPA), and National academy Press, Washington D.C., 1992 USA, reported that data submitted on acute oral toxicity in rats showed no negative effect upto a dose of $5 \mathrm{ml} / \mathrm{kg}$. Methanolic leaf and bark extracts showed an oral LD50 (Lethal dose, 50\%) of about $13 \mathrm{~g} / \mathrm{kg}$ in acute toxicity studies on mice's. Oral toxicity was evaluated in albino rats by orally single administration of doses $25 \mathrm{mg} / \mathrm{kg}, 50 \mathrm{mg} / \mathrm{kg}, 100 \mathrm{mg} / \mathrm{kg}$ respectively in three groups of rats. Observed for 6 weeks for progressively decrease of respiratory rates, pulses and body weight along with diarrhoea. The maximum tolerated safe oral dose of stem bark extract upto $100 \mathrm{mg} / \mathrm{kg}$ for six weeks in rats was safe. $100 \mathrm{mg} / \mathrm{kg}$ did not cause any death in rats. So, selected dose $(50 \mathrm{mg} / \mathrm{kg}$ and $100 \mathrm{mg} / \mathrm{kg}$ ) of Azadirachta indica stem bark extract has no toxicity effect. ${ }^{5}$

\section{Castor oil induced diarrhoea}

The animals (5 animal each group) were treated as follows

Group I (Normal control) : Received only vehicle (Saline $2 \mathrm{ml} / \mathrm{kg}$ ) orally

Group III (Standard) : Received Loperamide $2.5 \mathrm{mg} / \mathrm{kg}$ orally.

Group IV (stem bark extract-1) : Received the aqueous extract at the dose of 50mg/kg orally

Group V (stem bark extract-2) : Received the aqueous extract at the dose of $100 \mathrm{mg} / \mathrm{kg}$ orally.

After $30 \mathrm{~min}$ of the above treatment the diarrhoea was induced by using the oral administration of $0.2 \mathrm{ml}$ of castor oil to every rat. Each animal were keep housed in a individual cages, the cage of floor was lined by the blotting paper. The lining of floor was changed in every hour. Observed for four hrs, during observations period the total numbers of fecal output and the numbers of diarrhoaric faeces were recorded of the animals. Numbers of the both wet and dry dropping of diarrhoeal were counted at every hours for the period of 4 hours. $^{6}$

\section{Gastrointestinal motility test}

The animals were treated as follows

Group I (Normal control) : : Received only vehicle (Normal distilled water) orally

Group II (Standard) : : Received Atropine sulphate of the dose of $0.1 \mathrm{mg} / \mathrm{kg}$ orally.

Group III (stem bark extract-1) : Received the aqueous extract at the dose of $50 \mathrm{mg} / \mathrm{kg}$ orally

Group IV (stem bark extract-2) : Received the aqueous extract at the dose of $100 \mathrm{mg} / \mathrm{kg}$ orally.

After the $30 \mathrm{~min}$ of administration, orally given $1 \mathrm{ml}$ of activated charcoal meal to every animals $(10 \%$ activated charcoal in $5 \%$ of gum acacia). After $30 \mathrm{~min}$ of charcoal meal administration, every animal were sacrificed and the distance of the travelled by the charcoal meal in intestine was measure and expressed the percentage of move of distance. The travelled distance by charcoal in length of fraction was measured. 


\section{PGE2 (Prostaglandin E2 ) induced enteropooling}

The animals were treated as follows

Group I (Normal control)

Received only vehicle (Normal saline) orally

Group II (Standard)

Received $\mathrm{PGE}_{2}$ of the dose of $100 \mu / \mathrm{kg}$ orally.

Group III (stem bark extract-1) : Received the aqueous extract at the dose of $50 \mathrm{mg} / \mathrm{kg}$ orally

Group IV (stem bark extract-2) : Received the aqueous extract at the dose of $100 \mathrm{mg} / \mathrm{kg}$ orally.

After the 30 min of administration, orally given $1 \mathrm{ml}$ of aqueous gum acacia to every animal ( $0.2 \%$ of aqueous gum acacia). After 30 min of aqueous gum acacia administration, every animal were sacrificed and the complete length of the intestine from the pylorus to ceacum was dissected and contents of it were collected in the test tube and the volume was measured. The fluid volume of rat's intestine was measured.

\section{Statistical Analysis}

All data values expressed as MEAN \pm SEM. Statistical analysis data was done by ANOVA by following Dunnett's test. $p<0.05$ considered as significant.

\section{RESULTS}

The phytochemical evaluation of aqueous extract Azadirachta indica was shows presence of different different phytochemical constituents such as alkaloids, flavonoids, carbohydrate and reducing sugar, glycosides, Tannins, proteins and amino acids, and also triterpenoids and steroids was founded. In the aqueous extract of Azadirachta indica phytochemical component Saponins was absent, Saponins not found in aqueous extract.

\section{Effect of Castor oil induced diarrhoea}

In this model all test groups were compared with disease group on the behalf of stool passed by every group animals. The mean of the stools passed by all test groups was calculated. The aqueous extract of Azadirachta indica stem bark at the doses of $50 \mathrm{mg} / \mathrm{kg}$ and $100 \mathrm{mg} / \mathrm{kg}$, reduce the frequency of defecation and also the total weight of faeces significantly, in a dose dependent manner, and the results were statistically unique as summarized in table

Table 1: Effect of aqueous extract of Azadirachta indica stem bark in castor oil induced diarrhoea

\begin{tabular}{|l|c|c|}
\hline Treatment & Frequency of defecation & Total wt. of faeces \\
\hline Normal control & $5.466 \pm 0.412$ & $0.764 \pm 0.082$ \\
\hline Standard (Loperamide) & $3.358 \pm 0.427 \#$ & $2.034 \pm 0.214 \#$ \\
\hline Aq. Bark extract -1 & $3.795 \pm 0.237 \#$ & $2.816 \pm 0.161 \#$ \\
\hline Aq. Bark extract -2 & $3.498 \pm 0.237 \#$ & $2.357 \pm 0.161 \#$ \\
\hline
\end{tabular}

Values are expressed as MEAN $\pm \mathrm{SEM}$, of $\mathrm{n}=5$ per group. Where $\# \mathrm{p}<0.05$ when compared to normal control group.

The aqueous extract of the stem bark of Azadirachta indica at the doses of $50 \mathrm{mg} / \mathrm{kg}$ and $100 \mathrm{mg} / \mathrm{kg}$ reduces the total weight of faeces significantly which was almost similar to the effect of standard drug in the terms of the total weight of faeces.

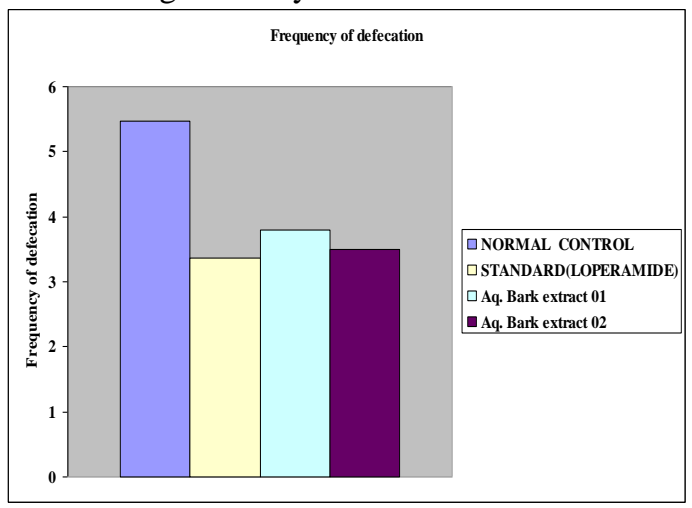

Fig 1 : Effect of aqueous extract of Azadirachta indica stem bark extract on frequency of defecation

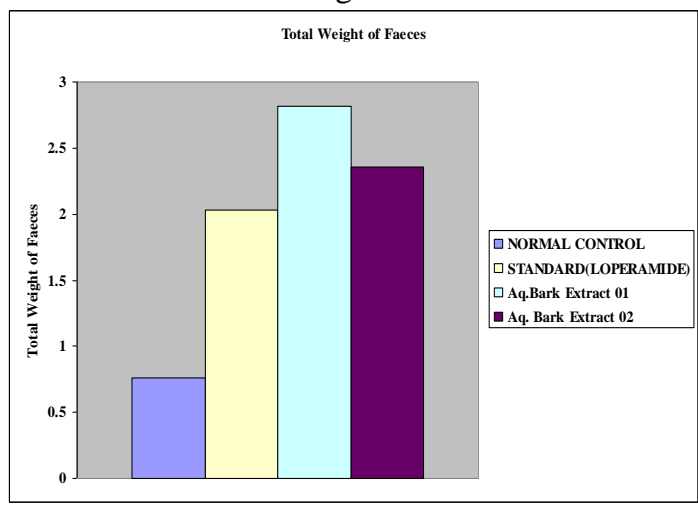

Fig 2 :Effect of aqueous extract of Azadirachta indica stem bark on weight of faeces. 


\section{Effect of Gastrointestinal motility test}

In the gastrointestinal motility test, the aqueous extract of stem bark at the dose of $100 \mathrm{mg} / \mathrm{kg}$ retarded the intestinal transit of charcoal meal in the rats as compared to the control group but at the dose of $50 \mathrm{mg} / \mathrm{kg}$ of stem bark extract not shows any significant delayed of intestinal transit of charcoal meal in the test of animals. On the basis of below data we said that the lower dose of stem bark extract not showed the significant result but the result of higher dose of stem bark extract nearby to standard result and the results was statically significant and summarized in table 2

Table 2 Effect of aqueous extract of Azadirachta indica stem bark in gastrointestinal motility test

\begin{tabular}{|l|c|}
\hline Treatment & Distance travelled by charcoal in intestine (\%) \\
\hline Normal control & $92.041 \pm 1.386$ \\
\hline Standard (Atropine sulphate) & $61.548 \pm 0.794$ \\
\hline Aq. ext. stem bark 01 & $81.492 \pm 1.306$ \\
\hline Aq. ext. stem bark 02 & $65.903 \pm 0.577$ \\
\hline
\end{tabular}

Values are expressed as MEAN \pm SEM, $n=5$ per group where, $\mathrm{p}<0.05$ when compared to normal control to using one way ANOVA followed by Dunnett's test.

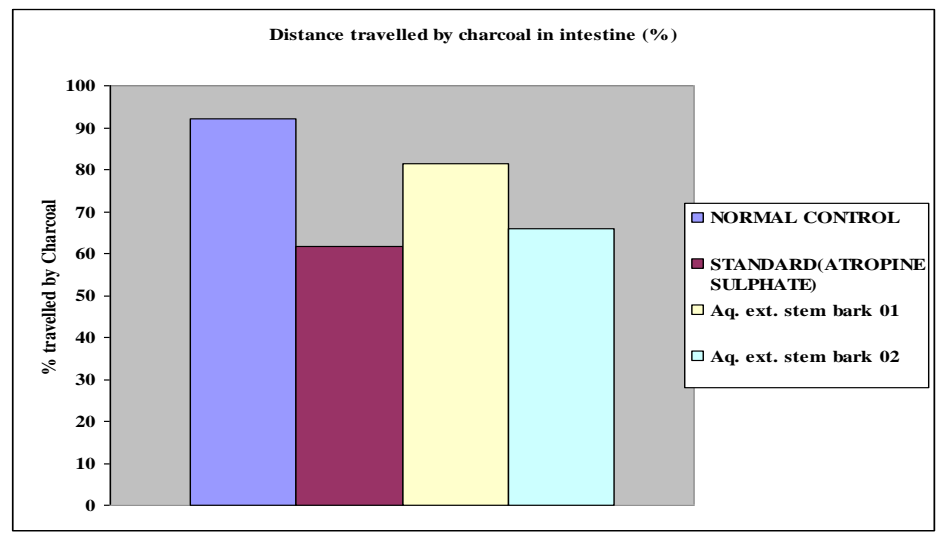

On the basis of above data we found that the antisecretary effect of the test drug is more prominent and can be attained the even at low dose but the antimotility effect of higher dose achieve better then low test dose of stem bark.

Figure 3 Effect of aqueous extract of Azadirachta indica stem bark on distance travelled by charcoal in intestine (\%)

\section{Effect of PGE 2 (Prostaglandin $\mathrm{E}_{2}$ ) induced enteropooling}

The both aqueous extract of the stem bark at the doses of $50 \mathrm{mg} / \mathrm{kg}$ and $100 \mathrm{mg} / \mathrm{kg}$ significantly inhibits PGE 2 induced enteropooling. In the $\mathrm{PGE}_{2}$ induced enteropooling significantly increases in fluid volume of animals intestine were observed when compared with control animals receiving's only in normal saline. The both aqueous extract of the stem bark significantly inhibits $\mathrm{PGE}_{2}$ induced enteropooling.

Table 3 Effect of aqueous extract of Azadirachta indica stem bark in PGE2 (Prostaglandin E2) test

\begin{tabular}{|l|c|}
\hline \multicolumn{1}{|c|}{ Treatment } & Volume of intestinal fluid \\
\hline Normal Control & $0.937 \pm 0.051$ \\
\hline Standard (PGE 2 Enteropooling) & $3.125 \pm 0.041$ \\
\hline Aq. ext. stem bark 01 & $2.037 \pm 0.081$ \\
\hline Aq. ext. stem bark 02 & $1.142 \pm 0.057$ \\
\hline
\end{tabular}

Values are expressed as MEAN \pm SEM, $n=5$ per group where, $\mathrm{p}<0.05$ when compared to normal control to using one way ANOVA followed by Dunnett's test.

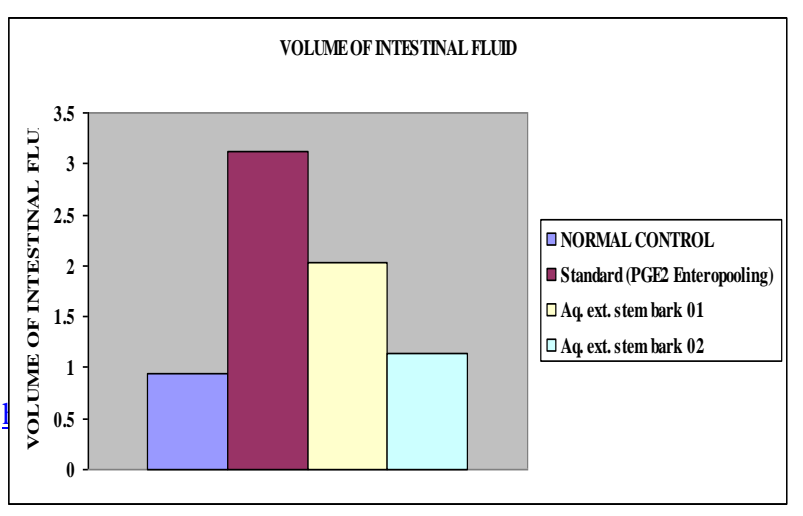

On the basis of above data we found that in the $\mathrm{PGE}_{2}$ induced enteropooling significantly increases in fluid volume of animal's intestine were observed when compared with control animals receiving's only in normal saline. The both aqueous extract of the stem bark at the doses of $50 \mathrm{mg} / \mathrm{kg}$ and $100 \mathrm{mg} / \mathrm{kg}$ significantly inhibits $\mathrm{PGE}_{2} \quad$ induced enteropooling. 
Figure 4 Effect of aqueous extract of Azadirachta indica stem bark in $\mathrm{PGE}_{2}$ (Prostaglandin $\mathrm{E}_{2}$ ) induced enteropooling.

\section{DISCUSSION}

The present study involve the evaluation of antidiarrhoeal activity of Azadirachta indica stem bark aqueous extract against castor oil induced diarrhoea in wistar rats and also study of the effect of aqueous stem bark extract on gastrointestinal motility and prostaglandin $\left(\mathrm{PGE}_{2}\right)$ induced enteropooling. In the castor oil induced diarrhoea method, after the administration of castor oil produced the semisolid diarrhoeal droppings in animals of control group during 4 hours of observations period. Both the doses of the test drug and aqueous extract of Azadirachta indica stem bark significantly $(\mathrm{p}<0.05)$ inhibited the frequency of defecation to $3.795 \pm 0.237$ in aqueous bark extract-1, $3.498 \pm 0.237$ in aqueous bark extract- 2 respectively. The standard drug Loperamide further decrease the diarrhoeal droppings to $3.358 \pm 0.427$, showing the significant antidiarrhoeal activity. Results according to above data the aqueous extract of the stem bark at the doses of $50 \mathrm{mg} / \mathrm{kg}$ and $100 \mathrm{mg} / \mathrm{kg}$ significantly reduce the frequency of defecation. In the terms of defecation the effect of aq. bark extract sample almost equal to the effect of the standard drug. For the measured data of weight of faeces in the castor oil induced diarrhoea method, after the administration of castor oil produced the semisolid diarrhoeal droppings in animals of control group during 4 hours of observations period. Both the doses of the test drug and aqueous extract of Azadirachta indica stem bark significantly $(\mathrm{p}<0.05)$ inhibited the weight of faeces to $2.816 \pm 0.161$ in aqueous bark extract- $1,2.357 \pm 0.161$ in aqueous bark extract-2 respectively. The standard drug Loperamide further decrease the diarrhoeal droppings to $2.034 \pm 0.214$, showing the significant antidiarrhoeal activity. Results according to above data the aqueous extract of the stem bark of Azadirachta indica at the doses of $50 \mathrm{mg} / \mathrm{kg}$ and $100 \mathrm{mg} / \mathrm{kg}$ reduces the total weight of faeces significantly which was almost similar to the effect of standard drug in the terms of the total weight of faeces. The gastrointestinal motility with activated was carried out for find out the effect of aqueous extract of stem bark on peristaltic movement in charcoal meal feed of the animals. The distance travelled by charcoal meal in standard group was found to be $61.548 \pm 0.794$ at 30 minutes as compared to normal control group amount was founded $92.041 \pm 1.386$ at 30 minutes. Distance travelled by charcoal in the plant aqueous extract-1 of stem bark was $81.492 \pm 1.306$ founded when animals treated with $50 \mathrm{mg} / \mathrm{kg}$ of dose. When dose increased upto $100 \mathrm{mg} / \mathrm{kg}$ dose respectively in aqueous extract- 2 of the stem bark then the distance travelled was founded $65.903 \pm 0.577(\mathrm{p}<0.05)$ after 30 minutes of evolutions. The results on the basis of above data we found that the antisecretary effect of the test drug is more prominent and can be attained the even at low dose but the antimotility effect of higher dose achieve better then low test dose of stem bark. The high dose of stem bark extract suppressed the transmission of charcoal meal in intestine and increased the water and electrolytes absorption in gut. In $\mathrm{PGE}_{2}$ induced enteropooling the both aqueous extract of the stem bark at the doses of $50 \mathrm{mg} / \mathrm{kg}$ and $100 \mathrm{mg} / \mathrm{kg}$ significantly inhibits $\mathrm{PGE}_{2}$ induced enteropooling. In the $\mathrm{PGE}_{2}$ induced enteropooling significantly increases in fluid volume of animals intestine were observed when compared with control animals receiving's only in normal saline. The both aqueous extract of the stem bark significantly inhibits $\mathrm{PGE}_{2}$ induced enteropooling. The fluid volume travelled by $\mathrm{PGE}_{2}$ in standard group was found to be $3.125 \pm 0.041$ at 30 minutes as compared to normal control saline group amount was founded $0.937 \pm 0.051$ at 30 minutes. Fluid volume of $\mathrm{PGE}_{2}$ induced diarrhoea by the plant aqueous extract- 1 of stem bark was founded $2.037 \pm 0.081$ when animals treated with $50 \mathrm{mg} / \mathrm{kg}$ of dose. When dose increased upto $100 \mathrm{mg} / \mathrm{kg}$ dose respectively in aqueous extract- 2 of the stem bark then the fluid volume of $\mathrm{PGE}_{2}$ induced diarrhoea was founded 1.142 \pm 0.057 $(\mathrm{p}<0.05)$ after 30 minutes of evolutions. The results founded on the basis of above data we found that in the $\mathrm{PGE}_{2}$ induced enteropooling significantly increases in fluid volume of animals intestine were observed when compared with control animals receiving's only in normal saline. The both aqueous extract of the stem bark at the doses of $50 \mathrm{mg} / \mathrm{kg}$ and $100 \mathrm{mg} / \mathrm{kg}$ significantly inhibits $\mathrm{PGE}_{2}$ induced enteropooling.

\section{CONCLUSION}

The aqueous extract of Azadirachta indica stem bark showed the antidiarrhoeal activity in the models of diarrhoeal conditional animals. The aqueous extracts of Azadirachta indica stem bark significantly decrease the propulsion of charcoal meal through the gastrointestinal track and also decreased the frequency of defecation and faecal droppings. Similarly the aqueous extracts of Azadirachta indica stem bark inhibit significantly $\mathrm{PGE}_{2}$ induced enteropooling. The both aqueous extracts of Azadirachta indica stem bark extract at the doses of $50 \mathrm{mg} / \mathrm{kg}$ and $100 \mathrm{mg} / \mathrm{kg}$ show the therapeutic effect against diarrhoea. So on the bases of these findings we can say that Azadirachta indica stem bark showed the antidiarrhoeal activity. It can be assumed that Azadirachta indica stem bark extract could be a potential source for novel lead discovery for antidiarrhoeal drug development.

\section{REFERENCES}

1. Dr. Ramesh K. Goyal, Dr. Anita A. Mehta, Dr. Guurang B.Shah ,Derasari \&gandhi’s ,Human Anatomy Physiology $\&$ health education, Disorder of digestive system, page no. 206. 
2. Tripathi, K.D., 2008. Essential of Medical Pharmacology; 6thedn, Jaypee Brothers Medical Publishers (P) LTD, New Delhi, pp. 656-664.

3. National formulary of India, (NFI-2011) Edition $4^{\text {th }}, 70-79$ page no.

4. Ashish Mishra, Ankit Seth, Santosh Kumar maurya, "Therapeutic significance and pharmacological activities of antidiarrhoeal medicinal plants mention in Ayurveda: a review, Vol 5, may 042016 , Journal of Intercultural Ethenopharmacology.

5. Abhishek raj, toxicological Effect of Azadirachta Indica, Asian journals of multidisciplinary Studies, volume 2, Issue 9, september 2014 .

6. T. Prakask, Bhoumic Dayanand, Shivakumar H, Venkatesh J.S., Dutta A.S., Antidiarrhoeal activity of Psidium guajava. Journal of Natural Remedies, Vol7/2 (2007).

\section{AUTHORS}

First Author* - Mr. Ankit Dhama, M.Pharm. (Pharmacology), Research Scholar, Translam institute of Pharmaceutical education \& Research, Meerut, Email: Jsrhkjsrhk@gmail.com

Second Author - Dr. Shamim Ahmad, PhD, Director, Translam institute of Pharmaceutical education \& Research, Meerut, Email: Pharma@translam.com.

Third Author - Mr. Praveen Kumar, M.Pharm., Associate Prof., Translam institute of Pharmaceutical education \& Research, Meerut.

Forth Author - Dr. Ashish K. Paharia, PhD, HOD, Pharmacology, Translam institute of Pharmaceutical education \& Research, Meerut.

Correspondence Author - Mr. Ankit Dhama Gurjar, Jsrhkjsrhk@ gmail.com, Jsrhajsrh@ gmail.com, +919997747518. 